\title{
Electrochemical and Gravimetric Corrosion Inhibition Investigations of A Heterocyclic Schiff Base Derived From 3- Formylindole.
}

\author{
${ }^{1}$ Aby Paul, ${ }^{2}$ Joby Thomas K, ${ }^{3}$ Vinod P Raphael, ${ }^{4}$ Shaju K S \\ Research Division, Department of Chemistry, St.Thomas' College (University of Calicut) Thrissur, Kerala, \\ India
}

\begin{abstract}
The corrosion inhibition efficiency of Schiff base, 3-formylindole-3-aminobenzoic acid (3FI3ABA) on mild steel (MS) in $1.0 \mathrm{M} \mathrm{HCl}$ solution have been investigated using weight loss measurements, electrochemical impedance spectroscopy (EIS) and potentiodynamic polarization studies. 3FI3ABA exhibited good inhibition on mild steel in $\mathrm{HCl}$ medium even at low concentrations and the inhibition efficiencies increases with increase in concentration of the inhibitor. The adsorption of inhibitor on the surfaces of the corroding metal obeys Langmiur isotherm. Polarization studies revealed that 3FI3ABA act as a mixed type inhibitor. Thermodynamic parameters $\left(K_{a d s}, \Delta G_{\text {ads }}^{0}\right)$ were calculated using Langmiur adsorption isotherm.
\end{abstract}

Keywords: Corrosion inhibitors, Impedance. Isotherm, Mild Steel, Schiff base,

\section{Introduction}

Schiff bases, are organic molecules possessing azomethine linkage $(\mathrm{C}=\mathrm{N})$, have innumerable advantages, right from pharmaceutical applications to the corrosion inhibitions, in the various fields of science. The hetero atoms present in these molecules are of key importance and are responsible for the corrosion inhibition in acidic media on the metal surface [1-3]. Some recently reported Schiff bases showed effective inhibition for mild steel (MS), Aluminum, Copper and Zinc in acidic media [4-11]. Enormous use of hydrochloric acid for acid pickling, de-scaling and cleaning process of mild steel surface are the major reasons for the corrosion problems in the world. Increasing efforts have been made to study the corrosion behavior of metals and mechanism of inhibition during the past decade mainly through electrochemical investigations $[8,9]$. Limited work has been reported for the corrosion inhibition of compounds derived from 3-formylindole in acid media. The present investigation was undertaken to examine the corrosion inhibition capacity and mechanism of inhibition of a novel heterocyclic Schiff base (3FI3ABA) molecules derived from 3-formylindole and 3aminobenzoic acid in $1 \mathrm{M} \mathrm{HCl}$ solution on MS. The study was performed using weight loss measurements, electrochemical impedance spectroscopy (EIS) and potentiodynamic polarization analysis.

\section{Inhibitor}

\section{Experimental}

Heterocyclic Schiff base was obtained by the condensation of equimolar mixture of 3 -formylindole and 3-amino benzoic acid in ethanol. The reaction mixture was refluxed for 2 hours, evaporated and cooled in ice bath to obtain yellow coloured compound. Figure 1 shows the molecular structure of heterocyclic Schiff base 3FI3ABA. Anal.calcd for $\mathrm{C}_{16} \mathrm{H}_{12} \mathrm{~N}_{2} \mathrm{O}_{2}$ : C, 72.72; H, 4.55; N, $10.61 ; \mathrm{O}, 12.12 \%$. Found. C, 70.96; H, $5.10 ; \mathrm{N}, 9.98 ; \mathrm{O}, 12.17 \% ; \mathrm{m} . \mathrm{p} .=180{ }^{\circ} \mathrm{C} ; \mathrm{IR}(\mathrm{KBr}): v_{\mathrm{C}=\mathrm{N}}=1600 \mathrm{~cm}^{-1} .{ }^{1} \mathrm{Hnmr}: \delta_{\mathrm{COOH}} 11.99, \delta_{\mathrm{CH}=\mathrm{N}} 9.79$, $\delta_{\mathrm{NH}} 6.83 .{ }^{13} \mathrm{Cnmr}: \delta_{\mathrm{COOH}} 187.56, \delta_{\mathrm{CH}=\mathrm{N}} 130.32$. Mass: $\mathrm{M}^{+}$peak m/z:264 (Base peak).<smiles>O=C(O)c1cccc(/N=C/c2c[nH]c3ccccc23)c1</smiles>

\section{Solutions}

Figure 1: Molecular Structure of 3FI3ABA

The aggressive solutions of $1 \mathrm{M} \mathrm{HCl}$ were prepared by dilution of A.R grade 37\% of $\mathrm{HCl}$ (Merck) with de-ionized water. Inhibitor solutions were prepared in the range, $0.1 \mathrm{mM}-1 \mathrm{mM}$ concentrations.

\section{Weight loss measurements}

Mild steel specimens of dimension $1.5 \times 2 \times 0.1 \mathrm{~cm}$ were cut abraded with various grades of silicon carbide papers $(200,400,600,800,1000,1200$ and 2000). The exact area and thickness of each coupon were measured and washed with distilled water containing detergent. Specimens were then degreased again with acetone and finally dried. After weighing with sensitive electronic balance, specimens were immersed in 50ml 
acid solutions (non-de aerated) at $28^{\circ} \mathrm{C}$ in the absence and presence of the inhibitor, 3FI3ABA, using hooks and fishing lines. Weight loss of metal specimens was noted at every $24 \mathrm{~h}$ time interval for five days. The experiments were carried out in duplicate and the average values were reported. The corrosion rate $(v)$ is calculated by the following equation [8].

$v=\frac{W}{S t}$

where $\mathrm{W}$ is the average weight loss of coupon, $\mathrm{S}$ is the total area of specimen and $\mathrm{t}$ is the time of treatment. The percentage of inhibition efficiency $(\eta)$ is defined by [12].

$\eta_{\mathrm{w}} \%=\frac{v 0-v}{v 0} \times 100$

where $v_{0}$ and $v$ are the corrosion rates of uninhibited and inhibited specimens respectively.

\section{Electrochemical Impedance Spectroscopy (EIS)}

The EIS measurements were performed in a three electrode assembly. Saturated calomel electrode (SCE) was used as the reference electrode. Platinum electrode having $1 \mathrm{~cm}^{2}$ area was taken as counter electrode. Metal specimens with an exposed area of $1 \mathrm{~cm}^{2}$ were used as the working electrode. The EIS experiments were carried out on a Ivium compactstat-e electrochemical system. $1 \mathrm{M} \mathrm{HCl}$ acid (no deaereation, no stirring) was taken as the electrolyte and the working area of the metal specimens were exposed to the electrolyte for $1 \mathrm{~h}$ prior to the measurement. EIS measurements were performed at constant potential (OCP) in the frequency range from $1 \mathrm{KHz}$ to $100 \mathrm{mHz}$ with amplitude of $10 \mathrm{mV}$ as excitation signal. The percentage of inhibitions from impedance measurements were calculated using charge transfer resistance values by the following expression [2]:

$\eta_{\text {EIS }} \%=\frac{\text { Rct }-R^{\prime} c t}{\text { Rct }} \times 100$ inhibitor respectively.

where $\mathrm{R}_{\mathrm{ct}}$ and $\mathrm{R}_{\mathrm{ct}}$ are the charge transfer resistances of working electrode with and without

\section{Potentiodynamic polarization}

Electrochemical polarization studies of MS specimens in $1 \mathrm{M} \mathrm{HCl}$ with and without inhibitor were performed by recording anodic and cathodic potentiodynamic polarization curves. Polarization plots were obtained in the electrode potential range from -100 to $+100 \mathrm{mV}$ Vs corrosion potential $\left(\mathrm{E}_{\text {corr }}\right)$ at a scan rate of $1 \mathrm{mV} / \mathrm{sec}$. Tafel polarization analysis were done by extrapolating anodic and cathodic curves to the potential axis to obtain corrosion current densities $\left(\mathrm{I}_{\text {corr }}\right)$. The percentage of inhibition efficiency $\left(\eta_{\mathrm{pol} \%}\right)$ was evaluated from the measured $\mathrm{I}_{\text {corr }}$ values using the following relation [13]:

$\eta_{\text {pol }} \%=\frac{\text { Icorr }- \text { I'corr }}{\text { Icorr }} \times 100$

where $\mathrm{I}_{\text {corr }}$ and $\mathrm{I}_{\text {corr }}$ are the corrosion current densities of the exposed area of the working electrode in the absence and presence of inhibitor.

From the slope analysis of the linear polarization curves in the vicinity of corrosion potential of blank and different concentrations of the inhibitor, the values of polarization resistance $\left(R_{p}\right)$ in $1 \mathrm{M} \mathrm{HCl}$ solution were obtained. From the evaluated polarization resistance, the inhibition efficiency was calculated using the relationship

$\eta_{\mathrm{Rp}} \%=\frac{\mathrm{R}^{\prime} \mathrm{p}-\mathrm{Rp}}{\mathrm{R}^{\prime} \mathrm{p}} \times 100$

respectively [2].

where $R_{p}^{\prime}$ and $R_{p}$ are the polarization resistance in the presence and absence of inhibitor

\section{Weight loss measurements}

III. Results And Discussion

The corrosion rates and inhibition efficiencies obtained for MS specimens for a period of $24 \mathrm{~h}$ are listed in Table 1. For MS specimens the corrosion rate markedly decreased with inhibitor concentration. This response is due to the fact that the surface coverage of the inhibitor molecules on the metal through adsorption increases with increase in concentration [14]. A maximum inhibition efficiency of $95 \%$ was obtained for $0.8 \mathrm{mM}$. Fig. 2 shows the variation inhibition efficiency with immersion time for the inhibitor concentrations $0.1,0.4$ and $0.8 \mathrm{mM}$. For 0.1 and $0.4 \mathrm{mM}$ concentrations the inhibition efficiencies rised up to $72 \mathrm{hr}$ and will not changed further considerably. For $0.8 \mathrm{mM}$ concentration, the percentage of inhibition efficiency almost remained as constant for the studied period. 
Electrochemical and Gravimetric Corrosion Inhibition Investigations of a heterocyclic Schiff Base

Table 1: The corrosion rate and percentage of inhibition efficiency obtained for MS specimens immersed in $1 \mathrm{M} \mathrm{HCl}$ at $28{ }^{\circ} \mathrm{C}$ for $24 \mathrm{~h}$ in the presence and absence of 3FI3ABA

\begin{tabular}{ccc}
\hline $\mathrm{C}(\mathrm{mM})$ & $\begin{array}{c}\text { Corrosion rate } \\
\left(\mathrm{mmy}^{-1}\right)\end{array}$ & $\begin{array}{c}\text { Inhibition } \\
\text { efficiency }\left(\eta_{\mathrm{w}} \%\right)\end{array}$ \\
\hline 0 & 4.23 & - \\
0.1 & 1.12 & 73.5 \\
0.2 & 1.02 & 75.8 \\
0.3 & 0.80 & 81.1 \\
0.4 & 0.76 & 82.2 \\
0.5 & 0.52 & 87.8 \\
0.6 & 0.45 & 89.4 \\
0.7 & 0.37 & 91.3 \\
0.8 & 0.21 & 95.0 \\
\hline
\end{tabular}

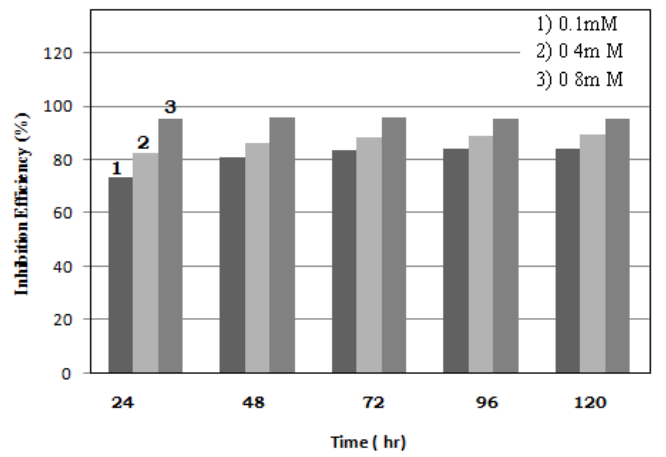

Figure 2: Variation of inhibition efficiency with immersion time

\section{Comparison of inhibition efficiency of Schiff base with its parent amine}

To compare the inhibition efficiencies of Schiff base and parent amine, weight loss measurements of MS specimens were performed in $1 \mathrm{M} \mathrm{HCl}$ at $28{ }^{\circ} \mathrm{C}$. The percentage of corrosion inhibition efficiencies obtained for Schiff base and parent amine on MS specimens is listed in Table 2. For MS specimens the inhibition efficiency of the Schiff base 3FI3ABA was markedly higher than that of 3-aminobenzoic acid for the studied concentrations. This investigation clearly establishes the role of azomethine linkage $(\mathrm{C}=\mathrm{N})$ present in the Schiff base which actively participate in the corrosion inhibition mechanism.

Table 2: Comparison of inhibition efficiency of Schiff base and parent amine

\begin{tabular}{ccc}
\hline \multirow{2}{*}{$\mathrm{C}(\mathrm{mM})$} & \multicolumn{2}{c}{ MS specimens $\left(\eta_{\mathrm{W} \%}\right)$} \\
\cline { 2 - 3 } & Parent Amine & Schiff base \\
\hline 0.1 & 48.9 & 73.5 \\
0.4 & 55.1 & 82.2 \\
0.7 & 67.1 & 91.3 \\
\hline
\end{tabular}

\section{Adsorption isotherm and free energy of adsorption}

The mechanism of adsorption and the surface behavior of organic molecules can be easily viewed through adsorption isotherms. Different models of adsorption isotherms considered are Langmiur, Temkin, Frumkin and Freundlich isotherms. For the evaluation of thermodynamic parameters it is necessary to determine the best fit isotherm with the aid of correlation coefficient $\left(\mathrm{R}^{2}\right)$. Among the isotherms mentioned above, the best description of the adsorption behavior of 3FI3ABA on MS specimens in $1 \mathrm{M} \mathrm{HCl}$ was Langmiur adsorption isotherm which can be expressed as $\frac{C}{\theta}=\frac{1}{K_{a d s}}+C$

where $C$ is the concentration of the inhibitor, $\theta$ is the fractional surface coverage and $K_{a d s}$ is the adsorption equilibrium constant [15]. Fig. 3 represents the adsorption plots of 3FI3ABA obtained by the weight loss measurements of MS steel specimens in $1 \mathrm{M} \mathrm{HCl}$ at $28{ }^{\circ} \mathrm{C}$. 


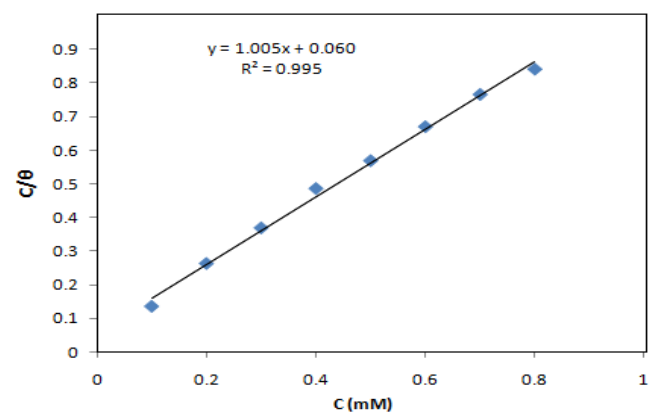

Figure 3: Langmiur adsorption isotherm for the adsorption of $3 \mathrm{FI} 3 \mathrm{ABA}$ on MS surface in $1 \mathrm{M} \mathrm{HCl}$ at $28{ }^{\circ} \mathrm{C}$

The adsorption equilibrium constant $K_{\text {ads }}$ is related to the standard free energy of adsorption $\Delta \mathrm{G}_{\text {ads }}^{0}$, by

$\Delta \mathrm{G}_{\mathrm{ads}}^{0}=-\mathrm{RT} \ln \left(55.5 \mathrm{~K}_{\mathrm{ads}}\right)$

Where 55.5 is the molar concentration of water, $\mathrm{R}$ is the universal gas constant and $\mathrm{T}$ is the temperature in Kelvin [16]. From the adsorption isotherm, $\mathrm{K}_{\mathrm{ads}}=16666 . \Delta \mathrm{G}_{\mathrm{ads}}^{0}$ for $3 \mathrm{FI} 3 \mathrm{ABA}$ on MS showed negative values indicating the spontaneity of the process. The value of $\Delta \mathrm{G}^{0}$ ads upto $-20 \mathrm{~kJ} \mathrm{~mol}^{-1}$ is an indication of the electrostatic interaction of the charged molecule and the charged surface of the metal (physisorption) while $\Delta \mathrm{G}^{0}$ ads is more negative than $-40 \mathrm{~kJ}$ implies that inhibitor molecules are adsorbed strongly on the metal surface through co-ordinate type bond(chemisorption) [16-18]. In the present investigation, 3FI3ABA molecules showed $\Delta \mathrm{G}_{\text {ads }}^{0}-34.4 \mathrm{~kJ}$ suggesting that the adsorption of inhibitor involves both electrostatic-adsorption and chemisorptions on MS.

\section{EIS measurements}

The corrosion response of $\mathrm{MS}$ in $1 \mathrm{M} \mathrm{HCl}$ in the presence and absence of inhibitor has been investigated using Electrochemical Impedance Spectroscopy at $28^{\circ} \mathrm{C}$. Fig. 4 represents the Nyquist plots of MS specimens in $1 \mathrm{M} \mathrm{HCl}$. It is evident from the plots that the impedance response of metal specimens showed a marked difference in the presence and absence of the inhibitor 3FI3ABA.

The semicircles showed slight irregularity which may be attributed to the roughness or non homogeneous nature of the metal surface [19-22]. The capacitance loop intersects the real axis at higher and lower frequencies. At high frequency end the intercept corresponds to the solution resistance $\left(\mathrm{R}_{\mathrm{s}}\right)$ and at lower frequency end corresponds to the sum of $R_{s}$ and charge transfer resistance $\left(R_{c t}\right)$. The difference between the two values gives $R_{c t}$. The value of $R_{c t}$ is a measure of electron transfer across the exposed area of the metal surface and it is inversely proportional to rate of corrosion [23].

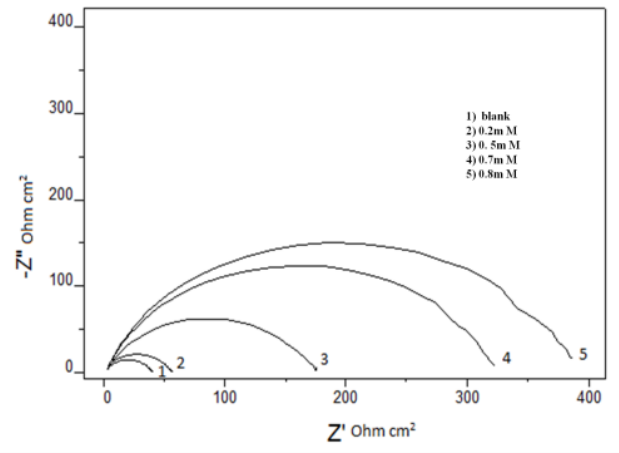

Figure 4: Nyquist plots for MS specimens in $1 \mathrm{M} \mathrm{HCl}$

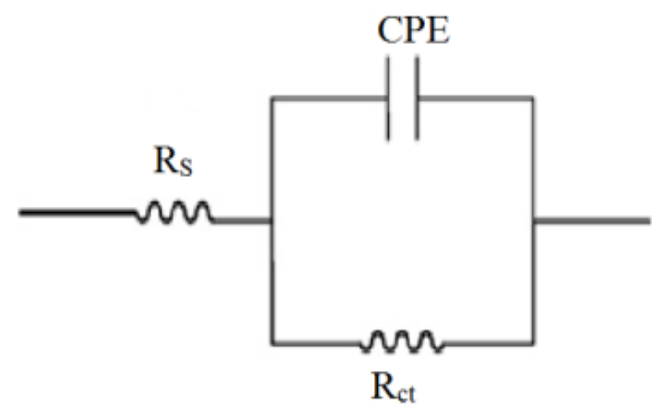

Figure 5: Equivalent circuit fitting for EIS

Impedance behaviour can be well explained by pure electric models that could verify and enable to calculate numerical values corresponding to the physical and chemical properties of electrochemical system under examination [24]. The simple equivalent circuit that fit to many electrochemical system composed of a double layer capacitance, $R_{s}$ and $R_{c t}[5,25,26]$. To reduce the effects due to surface irregularities of metal, constant phase element (CPE) is introduced into the circuit instead of a pure double layer capacitance which gives more accurate fit [27] as shown in the Fig. 5.

The impedance of CPE can be expressed as $Z_{C P E}=\frac{1}{Y_{0}(j \omega)^{n}}$

Where $\mathrm{Y}_{0}$ is the magnitude of CPE, $n$ is the exponent (phase shift), $\omega$ is the angular frequency and $\mathrm{j}$ is the imaginary unit. CPE may be resistance, capacitance and inductance depending upon the values of $n$ [5]. In all experiments the observed value 
of $n$ ranges between 0.8 and 1.0, suggesting the capacitive response of CPE. The EIS parameters such as $R_{\mathrm{ct}}, \mathrm{R}_{\mathrm{s}}$ and CPE and the calculated values of percentage of inhibition ( $\left.\eta_{\mathrm{EIS} \%}\right)$ are listed in Table 3.

Table 3: Electrochemical Impedance parameters of MS specimens, in $1 \mathrm{M} \mathrm{HCl}$ at $28{ }^{\circ} \mathrm{C}$ in the absence and presence of 3FI3ABA

\begin{tabular}{ccccc}
\hline $\begin{array}{c}\mathrm{C} \\
(\mathrm{mM})\end{array}$ & $\begin{array}{c}\mathrm{R}_{\mathrm{ct}} \\
\left(\Omega \mathrm{cm}^{2}\right)\end{array}$ & $\begin{array}{c}\mathrm{CPE} \\
\left.(\mu \mathrm{F} \mathrm{cm})^{-2}\right)\end{array}$ & $\begin{array}{c}\mathrm{R}_{\mathrm{s}} \\
\left(\Omega \mathrm{cm}^{2}\right)\end{array}$ & $\eta_{\mathrm{EIS} \%}$ \\
\hline 0 & 33.0 & 97.06 & 5.42 & - \\
0.2 & 47.9 & 78.72 & 5.84 & 31.1 \\
0.5 & 151.0 & 91.31 & 13.06 & 78.1 \\
0.7 & 288.0 & 62.09 & 17.59 & 88.5 \\
0.8 & 348.0 & 53.73 & 20.04 & 90.5 \\
\hline
\end{tabular}

From Table 3 it is clear that $R_{c t}$ values are increased with increasing inhibitor concentration. Decrease in capacitance values CPE with inhibitor concentration can be attributed to the decrease in local dielectric constant and /or increase in the thickness of the electrical double layer. This emphasis the action of inhibitor molecules by adsorption at the metal-solution interface [28]. The percentage of inhibitions $\left(\eta_{\mathrm{EIS} \%}\right)$ showed a regular increase with increase in inhibitor concentration. A maximum of $90.5 \%$ inhibition efficiency could be achieved at an inhibitor concentration of $0.8 \mathrm{mM}$.

\section{Potentiodynamic polarization studies}

Potentiodynamic polarization curves for 3FI3ABA in 1M HCl on MS specimens are shown in Fig.6. Polarization parameters like corrosion current densities $\left(\mathrm{I}_{\text {corr }}\right)$, corrosion potential $\left(\mathrm{E}_{\text {corr }}\right)$, cathodic Tafel slope $\left(b_{c}\right)$, anodic Tafel slope $\left(b_{a}\right)$, and inhibition efficiency $\left(E_{p}\right)$ are listed in Table 4. A prominent decrease in the corrosion current density $\left(\mathrm{I}_{\text {corr }}\right)$ was observed in the presence of inhibitor 3FI3ABA. A lowest value of $\mathrm{I}_{\text {corr }}$ was noticed for the inhibitor solution of concentration $0.8 \mathrm{mM}$ which exhibited a maximum inhibition efficiency of $90 \%$. Since the value of $b_{a}$ changes appreciably in the presence of 3FI3ABA, it may be assumed that the inhibitor molecules are more adsorbed on anodic sites. Generally if the shift of $\mathrm{E}_{\text {corr }}$ is $>85$ with respect to $\mathrm{E}_{\text {corr }}$ of uninhibited solution, the inhibitor can be viewed as cathodic or anodic type $[18,29,30]$. In the present study the maximum shift of $\mathrm{E}_{\text {corr }}$ is $25 \mathrm{mV}$, suggesting that $3 \mathrm{FI} 3 \mathrm{ABA}$ acts as a mixed type inhibitor for MS specimens in $1 \mathrm{MHCl}$. Similar results were reported by Sam John et al [9].

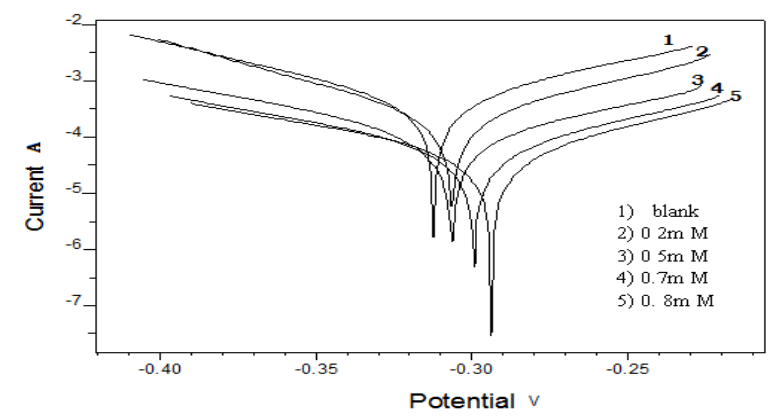

Figure 6: Tafel plots of MS specimens in $1 \mathrm{M} \mathrm{HCl}$ at $28{ }^{\circ} \mathrm{C}$, with and without inhibitor

\section{Mechanism of Inhibition}

It is well known that the surface of the metal is positively charged in acidic media [31]. It is believed that the $\mathrm{Cl}^{-}$ions could be specifically adsorbed on the metal surface and creates an excess of negative charge on the surface. This will favour the adsorption of protonated Schiff base $\left(3 \mathrm{FI} 3 \mathrm{ABAH}^{+}\right)$on the surface and hence reduce the dissolution of $\mathrm{Fe}$ [32]. Besides this electrostatic interaction between the protonated Schiff base and the metal surface other possible interactions are i) interaction of unshared electron pairs in the molecule with the metal ii) Interaction of $\pi$-electrons with the metal and iii) a combination of types (i-ii) [33-34]. If one examines the structure of Schiff base (3FI3ABA), many potential sources of inhibitor-metal interaction can be recognized. The unshared pair of electrons present on two $\mathrm{N}$ atoms is of key importance in making coordinate bond with the metal. The $\pi$-electron cloud of the aromatic rings and the azomethine linkage also participate in the inhibition mechanism. Furthermore, the double bonds in the inhibitor molecule permit the back donation of metal d electrons to the $\pi^{*}$ orbital and this type of interaction cannot occur with amines [35]. This can be justified by the lower inhibition efficiency of the parent amine than that of Schiff base. 
Electrochemical and Gravimetric Corrosion Inhibition Investigations of a heterocyclic Schiff Base

Table 4: Potentiodynamic polarization parameters of MS specimens in $1 \mathrm{M} \mathrm{HCl}$ at $28{ }^{0} \mathrm{C}$ in the absence and presence of 3FI3ABA

\begin{tabular}{|c|c|c|c|c|c|c|c|}
\hline & & Tafel Data & & & & $\begin{array}{l}\text { Linear } \\
\text { data }\end{array}$ & Dlarization \\
\hline $\mathrm{c}(\mathrm{mM})$ & $\begin{array}{c}\mathrm{E}_{\text {corr }} \\
(\mathrm{mV} / \mathrm{SCE})\end{array}$ & $\begin{array}{c}\mathrm{I}_{\text {corr }} \\
\left(\mu \mathrm{A} / \mathrm{cm}^{2}\right)\end{array}$ & $\begin{array}{c}\mathrm{b}_{\mathrm{c}} \\
(\mathrm{mV} / \mathrm{dec})\end{array}$ & $\mathrm{b}_{\mathrm{a}}(\mathrm{mv} / \mathrm{dec})$ & $\eta_{\text {pol } \%}$ & $\mathrm{R}_{\mathrm{p}}(\mathrm{ohm})$ & $\eta_{\mathbf{R p} \%}$ \\
\hline 0 & 482 & 362 & 98 & 75 & - & 41.2 & - \\
\hline 0.2 & 490 & 205 & 98 & 68 & 43.4 & 69.4 & 40.6 \\
\hline 0.5 & 493 & 80 & 103 & 88 & 78.0 & 205.2 & 79.9 \\
\hline 0.7 & 500 & 47 & 95 & 94 & 87.0 & 342.2 & 88.0 \\
\hline 0.8 & 507 & 39 & 92 & 99 & 89.2 & 431.1 & 90.4 \\
\hline
\end{tabular}

\section{Conclusions}

1. $3 \mathrm{FI} 3 \mathrm{ABA}$ is a good inhibitor for MS in $1 \mathrm{M} \mathrm{HCl}$. A maximum of $95 \%$ of inhibition efficiency could be achieved with this inhibitor by gravimetric investigation.

2. Compared to the parent amine, 3-aminobenzoic acid, the Schiff base 3FI3ABA exhibited higher inhibition efficiency.

3. The inhibition mechanism is explained by adsorption. Adsorption of Schiff base on MS surface obey Langmiur isotherm.

4. The thermodynamic parameters of the adsorption are calculated from the adsorption isotherms which showed that both physisorption and chemisorption are involved in the inhibition process.

\section{References}

[1] F. Bentiss, M. Traisnel, L. Gengembre and M. Lagrenée, Inhibition of acidic corrosion of mild steel by3,5-diphenyl-4H-1,2,4triazole, Applied Surface Science, 161(2), 2000, 194-202.

[2] A. Raman and P. Labine, Reviews on Corrosion Inhibitor Science and Technology,(vol. 1, NACE, Houston, TX , p.5,1986)

[3] E.E. Oguzie, Corrosion inhibition of mild steel in hydrochloric acid solution by methylene blue dye, Materials Letters, 59(8), 2005, 1076-1079.

[4] A. Yurt and Özlem Aykın, Diphenolic Schiff bases as corrosion inhibitors for aluminium in $0.1 \mathrm{M} \mathrm{HCl}$ : Potentiodynamic polarisation and EQCM investigations, Corrosion Science, 53(11), 2011, 3725-3732.

[5] A. K. Singh, S. K. Shukla, M. Singh and M.A. Quraishi, Inhibitive effect of ceftazidime on corrosion of mild steel inhydrochloric acid solution, Materials Chemistry and Physics, 129(1), 2011, 68-76.

[6] M. Behpour, S.M. Ghoreishi, N. Soltani, M. Salavati-Niasari, M. Hamadanian and A. Gandomi, Electrochemical and theoretical investigation on the corrosion inhibition of mild steel by thiosalicylaldehyde derivatives in hydrochloric acid solution, Corrosion Science, 50(8), 2008, 2172-2181.

[7] K. Stanly Jacob and G. Parameswaran, Corrosion inhibition of mild steel in hydrochloric acid solution by Schiff base furoin thiosemicarbazone, Corrosion Science, 52(1), 2010, 224-228..

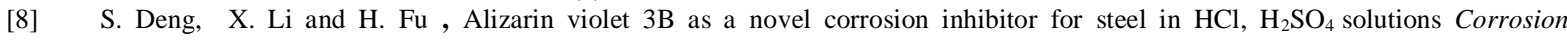
Science, 53(11), 2011, 3596-3602.

[9] S. John and A. Joseph, Electro analytical, surface morphological and theoretical studies on the corrosion inhibition behavior of different 1,2,4-triazole precursors on mild steel in $1 \mathrm{M}$ hydrochloric acid, Materials Chemistry and Physics, 133(2), 2012, 10831091.

[10] A. Bansiwal,P. Anthony, and S.P Mathur, Inhibitive effect of some Schiff bases on corrosion of aluminium in hydrochloric acid solutions, British Journal of Corrosion, 35(4), 2000, 301-303.

[11] S. Li, S. Chen, S. Lei, H. Ma, R. Yu and D. Liu, Investigation on some Schiff bases as HCl corrosioninhibitors for copper, Corrosion Science,41(7), 1999, 1273-1287, 1999.

[12] AST G-31-72, Standard recommended practice for the laboratory immersion corrosion testing of metals,ASTM, Philadelphia, PA, p.401, 1990 .

[13] H. Ashassi-Sorkhabi, B. Shaabani and D. Seifzadeh, Effect of some pyrimidinic Shciff bases on the corrosionof mild steel in hydrochloric acid solution, Electrochimica Acta, 50(16), 2005, 3446-3452.

[14] I.B. Oboz and N.O. Obi-Egbedi, Adsorption properties and inhibition of mild steel corrosion in sulphuric acid solution by ketoconazole: Experimental and theoretical investigation, Corrosion Science, 52(1), 2010, 198-204.

[15] X. Li, S. Deng, H. Fu, and T. Li, Adsorption and inhibition effect of 6-benzylaminopurine on cold rolled steelin1.0 M HCl, Electrochimica Acta, 54(16), 2009, 4089-4098.

[16] E. Cano, J.L. Polo, A.La Iglesia, and J.M. Bastidas ,A Study on the Adsorption of Benzotriazole on Copper in Hydrochloric Acid Using the Inflection Point of the Isotherm, Adsorption 10(3), 2004, 219225.

[17] F. Bentiss, M. Lebrini and M. Lagrenée, Thermodynamic characterization of metal dissolution and inhibitor adsorption processes in mild steel/2,5-bis(n-thienyl)-1,3,4-thiadiazoles/hydrochloric acid system, Corrosion Science, 47(12), 2005, 2915-2931.

[18] W. Li, Q. He, S. Zhang, C. Pei and B. Hou, Some new triazole derivatives as inhibitors for mild steel corrosion in acidic medium, Journal of Applied Electrochemistry, 38(3), 2008, 289-295.

[19] H. H. Hassan, E. Abdelghani and M. A. Amin, Inhibition of mild steel corrosion in hydrochloric acid solutionby triazole derivatives: Part I. Polarization and EIS studies, Electrochimica Acta, 52(22), 2007, 6359-6366.

[20] M.S Abdel-Aal, and M.S, Morad, Inhibiting effects of some quinolines and organic phosphonium compounds on corrosion of mild steel in 3M HCl solution and their adsorption characteristics, British Journal of Corrosion 36(4), 2001, 253-260.

[21] P. Bommersbach, C. Alemany-Dumont, J.P. Millet and B. Normand, Formation and behaviour study of an environment-friendly corrosion inhibitor by electrochemical methods, Electrochimica Acta, 51(6), 2005, 1076-1084.

[22] F. Mansfeld, Recording and Analysis of AC Impedance Data for Corrosion Studies, Corrosion, 37( 5), 1981, 301-307.

[23] I.L. Rosenfield, Corrosion Inhibitors (McGraw-Hill, New York ,p.66, 1981). 
[24] A. R. Sathiya Priya, V. S. Muralidharan, and A. Subramania, Development of Novel Acidizing Inhibitors for Carbon Steel Corrosion in 15\% Boiling Hydrochloric Acid. Corrosion,64(6), 2008, 541-552.

[25] M. El Azhar, B. Mernari, M. Traisnel, F. Bentiss and M. Lagrenée, Corrosion inhibition of mild steel by the new class of inhibitors [2,5-bis(n-pyridyl)-1,3,4-thiadiazoles] in acidic media, Corrosion Science, 43(12), 2001, 2229-2238.

[26] A. Yurt, A. Balaban, S.Ustün Kandemir, G. Bereket and B. Erk, Investigation on some Schiff bases as HCl corrosion inhibitors for carbon steel, Materials Chemistry and Physics, 85(2), 2004, 420-426.

[27] J.R.Macdonald, W.B. Johnson and J.R.Macdonald, Theory in impedance Spectroscopy, (John Wiley \& Sons, New York ,1987).

[28] E. McCafferty and Norman Hackerman, Double Layer Capacitance of Iron and Corrosion Inhibition with Polymethylene Diamines, Journal of Electrochemical Society,119(2), 1972, 146-154.

[29] X. Li, S. Deng and H. Fu, Synergism between red tetrazolium and uracil on the corrosion of cold rolled steelinH $\mathrm{SO}_{4}$ solution, CorrosionScience, 51(6),2009,1344-1355.

[30] E.S Ferreira, C. Giacomelli, F.C Giacomelli and A. Spinell, Evaluation of the inhibitor effect of L-ascorbic acid on the corrosion of mild steel Materials Chemistry and Physics, 83(1), 2004, 129-134.

[31] Q. Qu, Z. Hao, S. Jiang, L. Li and W. Bai, Synergistic inhibition between dodecylamine and potassium iodide on the corrosion of cold rolled steel in $0.1 \mathrm{M}$ phosphoric acid, Materials and Corrosion, 59(11), 2008, 883-888.

[32] F. Bentiss, M. Traisnel and M. Lagrenee, The substituted 1,3,4-oxadiazoles: a new class of corrosion inhibitors of mild steel in acidic media, Corrosion Science, 42(1), 2000, 127-146.

[33] D. P. Schweinsberg, G.A. George, A. K. Nanayakkara and D. A. Steinert, The protective action of epoxy resins and curing agents inhibitive effects on the aqueous acid corrosion of iron and steel, Corrosion Science, 28(1), 1988, 33-42

[34] H Shokry, M Yuasa, I Sekine, R.M Issa, H.Y El-baradie and G.K Gomma Corrosion inhibition of mild steel by schiff base compounds in various aqueous solutions: part 1, Corrosion Science, 40(12), 1998, 2173-2186.

[35] A. K. Singh and M. A. Quraishi, Inhibiting effects of 5-substituted isatin-based Mannich bases on the corrosion of mild steel in hydrochloric acid solution, 40(7), 2010, 1293-1306. 